\title{
ESTUDIOS
}

\section{La protección social en las personas con discapacidad}

\author{
Gema Polonio de Dios'
}

Resumen: El objetivo del presente artículo es la reflexión de un tema crucial en el ámbito de la discapacidad: la protección social. El artículo explica qué se entiende por protección social, marco jurídico normativo y principios que la fundamentan entre los que destacan: la igualdad de oportunidades y no discriminación, considerado no solo un principio, sino también un derecho y como tal, consolidado en los diferentes textos jurídicos y la inclusión social, fin último que, tanto administraciones, organizaciones, familias e incluso las propias personas con discapacidad, luchan día a día para que sea una realidad efectiva y no solo una plasmación ideológica. Además el artículo explicita las medidas de acción positiva que los distintos gobiernos están obligados a llevar a cabo para garantizar este derecho y con ello una verdadera inclusión social. Entre ellas destacan: la accesibilidad, la educación y el empleo.

Palabras clave: discapacidad, igualdad y no discriminación, inclusión social, protección social.

Fecha de recepción: 13 de septiembre de 2016

Fecha de admisión: 8 de febrero de 2017.

\section{Social protection in handicapped people}

Abstract: The aim of this article is the reflection of a crucial issue in the field of disability: social protection. Explains what is meant by social protection, legal framework and principles that underlie it among which stand out:
La protection sociale chez les personnes handicapées

Résumé: Le but de cet article est la réflexion d'une question cruciale pour les personnes handicapées: la protection sociale. L'article explique ce que l'on entend par protection

' Departamento de Derecho Civil, Facultad de Derechoy Ciencias Empresariales, Universidad de Córdoba. 
equal opportunities and non-discrimination, considered not only a principle, but also a right and, as such, in different legal texts and social inclusion, ultimate end that both administrations, organizations, families, and even the people with disabilities they struggle every day to make it an effective reality and not only an ideological embodiment. In addition, explicit measures of positive action that Governments are obliged to carry out to ensure this right and thereby a real social inclusion. These include accessibility, education and job.

Key words: Handicapped people, protection, equality and non-discrimination, social inclusion.

\section{El derecho a la protección social}

Cuando se habla de protección hacia las personas con discapacidad puede hacerse desde una doble vertiente: por un lado, la protección social de las personas con discapacidad que supone el reconocimiento de una serie de derechos sociales específicos para este colectivo, los cuales responden a sus necesidades peculiares y que se manifiestan como la respuesta a determinados problemas sociales. $Y$ por otro, de la protección jurídico-privada, cuyo legislador civil sólo atiende, en ocasiones, a través de escasas y deficientes medidas protectoras ${ }^{2}$. Así pues, la

\footnotetext{
2 Entre las medidas que recoge nuestro Código Civil destacan por un lado, las disposiciones "inter vivos", como pueden ser: $1^{\circ}$ ) apoderamiento preventivo, $2^{\circ}$ ) el contrato de alimentos, $3^{\circ}$ ) el patrimonio protegido y $4^{\circ}$ ) la hipoteca inversa. Y por otro, dentro de las disposiciones "mortis causa": $1^{\circ}$ ) posibilidad de gravar la legítima estricta a través de una sustitución fideicomisaria a favor de hijo o descendiente incapacitado judicialmente, una nueva causa de indignidad por la cual se impide que puedan heredar a una persona con discapacidad los parientes que no le hayan prestado las atenciones debidas durante su vida, $2^{\circ}$ ) la constitución (voluntaria o legal) de un derecho de habitación sobre la vivienda habitual a favor de un legitimario con discapacidad y $3^{\circ}$ ) la exclusión de la colación de los gastos realizados por los padres y ascendientes para cubrir las necesidades especiales de sus hijos o descendientes con discapacidad.
} 
protección social de las personas con discapacidad entendida como el conjunto de derechos sociales específicos, también encuentra su formulación en diferentes leyes que han sentado las bases y precedentes para la actuación en el ámbito internacional, estatal y autonómico. Todo este conjunto de normas jurídicas destinadas a las personas con discapacidad cumplen una función, a mi entender, protectora, que se configura como una acción solidaria tendente a la completa normalización e integración de estos ciudadanos en la sociedad.

\section{I.I.Análisis conceptual y regulación normativa}

La protección social como conjunto de derechos sociales tiene entre sus objetivos garantizar un mínimo de bienestar a todos aquellos que no están, o no lo suficientemente cubiertos por los modelos existentes de Seguridad Social. En este sentido, el concepto de "protección social" recogido en el informe del Secretario General de Naciones Unidas, Kofi Annan (2001), premio Nobel de la Paz, señaló como primera aproximación que

la protección social es un concepto amplio, que incluye una variedad de medidas normativas, no solamente pensiones, sino también atención a la salud, prestaciones familiares, seguros de desempleo, protección por discapacidad, rehabilitación y, en muchos países, asistencia social. La protección social es una inversión. La asignación de recursos a la protección social beneficia no sólo a los destinatarios sino a la sociedad en su conjunto ${ }^{3}$.

Siguiendo esta línea, el Comité de Protección Social (CPS) ${ }^{4}$ creado en virtud de lo establecido en el artículo 160 Tratado de la Unión Europea (TUE), define la protección social como:

Toda intervención de los órganos públicos o privados destinados a aliviar a las familias y a los individuos a una serie de determinados riesgos o necesidades, sin que ello implique ningún acto simultaneo ni ninguna disposición individual.

\footnotetext{
${ }^{3}$ Véase el discurso del Secretario General de Naciones Unidas en http://www.un.org/es/sg/formersg/ messages_annan.shtml

${ }^{4}$ Órgano consultivo creado en virtud de la Decisión 2004/689/CE del Consejo, de 4 de octubre de 2004 cuyo art. 1 dice así:

Por la presente Decisión se crea un Comité de protección social (denominado en lo sucesivo "el Comité») de carácter consultivo, para fomentar la coordinación entre los Estados miembros en materia de protección social, respetando plenamente las disposiciones del Tratado y teniendo debidamente en cuenta las competencias de las instituciones y órganos de la Comunidad.
} 
Este nuevo órgano, tendrá como finalidad única promover la cooperación sobre políticas de protección social entre los Estados miembros y la Comisión de Desarrollo 5 . Así pues, La Unión Europea, a raíz de la creación de este órgano consultivo, ha comenzado a fomentar una colaboración más estrecha entre los Estados miembros en materia de modernización de los sistemas de protección social ${ }^{6}$. A tal fin, la Comisión aprobará su informe sobre la protección social cada año, y no cada dos años como anteriormente se hacía. Este informe se redactará en colaboración con los Estados miembros y reflejará los grandes objetivos que deberá adoptar el Consejo en el marco de la estrategia concertada.

Ciñéndonos al ámbito de la discapacidad, años más tarde, tras la aprobación de la Convención Internacional de los Derechos de las Personas con Discapacidad en 2006, este acuerdo de colaboración entre los estados partes, se recogió de forma expresa en su articulado. Pero no sólo aparece recogido este convenio de coparticipación entre Estados, sino que además, se garantiza un nivel de vida adecuado y la protección social de las personas con discapacidad. Además, se insta a los Estados partes a seguir actuando en esta línea de cooperación ya definida, para la salvaguarda de este derecho ${ }^{7}$. Aunque no especifica qué se entiende por adecuado ni cuál son los recursos que se necesitarían para satisfacer este requerimiento, constituye todo un desafío y avance en el tema de exigibilidad de derechos sociales, sin olvidar que la nueva forma de protección social reviste un objetivo principal: contribuir a la lucha contra las formas de exclusión y apoyar a individuos o colectivos concretos ante los obstáculos sociales que, debido a la magnitud de los mismos, no son capaces de superar

${ }^{5}$ El art. 160 del TUE establece:

El Consejo, por mayoría simple, previa consulta al Parlamento Europeo, creará un Comité de Protección Social, de carácter consultivo, para fomentar la cooperación en materia de protección social entre los Estados miembros y con la Comisión. El Comité tendrá por misión: - supervisar la situación social y la evolución de las políticas de protección social de los Estados miembros y de la Unión, - facilitar el intercambio de información, experiencias y buenas prácticas entre los Estados miembros y con la Comisión, - sin perjuicio de lo dispuesto en el artículo 240, elaborar informes, emitir dictámenes o emprender otras actividades en los ámbitos que sean de su competencia, ya sea a petición del Consejo o de la Comisión, ya por propia iniciativa.

${ }^{6}$ Así lo recoge el TUE en su artículo 153.1. Letra (K)

7 El artículo 28 de la CIDPD señala:

Los Estados Partes reconocen el derecho de las personas con discapacidad a un nivel de vida adecuado para ellas y sus familias, lo cual incluye alimentación, vestido y vivienda adecuados, y a la mejora continua de sus condiciones de vida, y adoptarán las medidas pertinentes para salvaguardar y promover el ejercicio de este derecho sin discriminación por motivos de discapacidad. 2. Los Estados Partes reconocen el derecho de las personas con discapacidad a la protección social y a gozar de ese derecho sin discriminación por motivos de discapacidad. 
por sí mismo porque no tienen los recursos o medios materiales o económicos necesarios para ello.

A nivel estatal, en la Constitución Española (CE), lo relativo a la protección social con carácter general, se encuentra recogido básicamente en el Capítulo III del Título Primero referido a los principios rectores de la Política Social y Económica

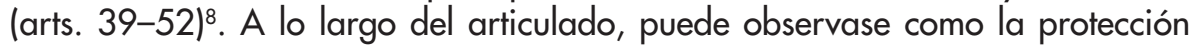
social aglutina este conjunto de principios que afecta a cualquier ámbito de la vida (económico, jurídico, familiar, medio ambiente, salud...) y como los poderes públicos velarán por el cumplimiento de todo lo establecido garantizando a los ciudadanos "la protección" requerida. Nuestra norma suprema pone de manifiesto con ello, la extensión de la protección social a cualquier esfera sea de la índole o característica que sea incluyendo la discapacidad. En base a ello, puede corroborarse el sentido extenso, amplio, dilatado y prolongado que caracteriza la protección social.

Siendo guía y modelo nuestra Constitución, en materia de discapacidad, el Real Decreto Legislativo 1/2013, de 29 de noviembre, por el que se aprueba el Texto Refundido de la Ley General de Derechos de las Personas con Discapacidad y de su Inclusión Social (LGDPD) dedica todo su Título VII (arts. 48-52) al derecho a la protección social ${ }^{9}$. No sólo se ampara en el texto constitucional sino que además sigue fielmente lo establecido en la Convención Internacional de los Derechos de las Personas con Discapacidad (CIDPD). Sobre el contenido de este derecho, la ley es lo suficientemente precisa a la hora de abordar esta cuestión y señala en su artículo 50, una serie de medidas específicas ${ }^{10}$.

${ }^{8}$ El art. 39.1 de la CE establece: "Los poderes públicos aseguran la protección social, económica y jurídica de la familia".

9 Señala el art. 48 LGDPD, Derecho a la protección social:

Las personas con discapacidad y sus familias tienen derecho a unos servicios y prestaciones sociales que atiendan con garantías de suficiencia y sostenibilidad sus necesidades, dirigidos al desarrollo de su personalidad y su inclusión en la comunidad, incrementando su calidad de vida y bienestar social.

${ }^{10}$ Según establece el art.50 LGDPD. Contenido del derecho a la protección social:

1. Las personas con discapacidad y sus familias tienen derecho a los Servicios Sociales de apoyo familiar, de prevención de deficiencias y de intensificación de discapacidades, de promoción de la autonomía personal, de información y orientación, de atención domiciliaria, de residencias, de apoyo en su entorno, servicios residenciales, de actividades culturales, deportivas, ocupación del ocio y del tiempo libre. 2. Además, y como complemento de las medidas específicamente previstas en esta ley, la legislación autonómica podrá prever servicios y prestaciones económicas para las personas con discapacidad y sus familias que se encuentren en situación de necesidad y que carezcan de los recursos indispensables para hacer frente a la misma. 
En nuestra Comunidad autónoma, el Estatuto Autonómico de Andalucía (EAA), según señala González Ortega (2012), ha recogido todas las manifestaciones de las políticas sociales existentes bajo la denominación de protección social ${ }^{1}$. Es el caso de la igualdad, educación, empleo estable y de calidad, participación e integración, protección a la familia y menores, vivienda, etc. Todas estas cuestiones se reparten entre el Título Preliminar (art 10.3) donde se recogen todos los objetivos básicos que la Comunidad persigue (especialmente los relacionados con la discapacidad apartados 15 y 16) y el Capítulo II del Título Primero (arts. 15 a 37) ${ }^{12}$. En realidad, en términos de derecho, el Estatuto de Autonomía añade poco a lo que ya establece la Constitución porque sin duda alguna, los Estatutos de Autonomía no pueden regular derechos fundamentales, sólo pueden incluir declaraciones, enunciados o tablas de derechos que tendrán el valor de principios rectores y cuya eficacia jurídica queda supeditada a la legislación autonómica ordinaria de desarrollo (STC 247/2007 de 12 diciembre) ${ }^{13}$.

Visto el reconocimiento legal de la protección social donde quedan englobadas las personas con discapacidad como sector especialmente vulnerable, es preciso delimitar a continuación la base de los principios sobre los que se asienta, unos principios sólidos y de gran calado, sin los cuales, no podría hablarse de una protección social real y efectiva. El cumplimiento de los mismos hace posible que este derecho sea una garantía para las personas con discapacidad y acicate para una auténtica inclusión social.

11 GonzÁlez Ortega, S. (2012) pp. 267-268.

12 Señala el art .10.3:

la Comunidad Autónoma, en defensa del interés general, ejercerá sus poderes con los siguientes objetivos básicos: $14^{\circ} \mathrm{La}$ cohesión social, mediante un eficaz sistema de bienestar público, con especial atención a los colectivos y zonas más desfavorecidos social y económicamente, para facilitar su integración plena en la sociedad andaluza, propiciando así la superación de la exclusión social. $15^{\circ}$ La especial atención a las personas en situación de dependencia. 16. ' La integración social, económica y laboral de las personas con discapacidad.

${ }^{13}$ STC 247/2007 de 12 de diciembre (BOE 15 de Enero 2008). Ponente: Excma. Sra. Magistrada $D^{a}$ Elisa Pérez Vera. 


\section{Principios que garantizan la Protección Social}

\section{I. La Igualdad de Oportunidades y No Discriminación}

Hablar hoy en día de igualdad de oportunidades y no discriminación es hablar de un de los temas más recurrentes de las teorías contemporáneas pues la atención a la discapacidad desde un enfoque de igualdad, no se ha producido solo en el ámbito filosófico, sino también, en el jurídico. Según establecen Vega y López (2011),

las personas con discapacidad se hallan entre las más vulnerables ya que sus limitaciones suponen un obstáculo para disfrutar de una plena autonomía y libertad lo que, sin duda, impide su pleno desarrollo ciudadano. Si aceptamos que las personas con limitaciones de cualquier tipo son conciudadanos, con los mismos derechos básicos de cualquier otra persona, se deduce que debemos esforzarnos para garantizar que se les dé también a ellos el mismo tipo de oportunidades para participar en la vida de su comunidad ${ }^{14}$.

Pero ¿qué se entiende por igualdad de oportunidades? Ríos de tinta se han escrito sobre este principio a los largo de las últimas décadas, veamos que aporta la doctrina.

Según Tuset (2011) se entiende por igualdad de oportunidades,

la ausencia de toda discriminación, directa o indirecta por motivo de discapacidad, incluida cualquier distinción, exclusión o restricción que tenga el propósito o el efecto de obstaculizar o dejar sin efecto el reconocimiento, goce o ejercicio en igualdad de condiciones por las personas con discapacidad, de todos los derechos humanos y libertades fundamentales en los ámbitos político, económico, social, cultural, civil o de otro tipo ${ }^{15}$.

Otra aportación distinta, la ofrece Bobbio (1993) quien distingue por un lado, entre igualdad de oportunidades e igualdad de resultado. Señala que

la igualdad de oportunidades apunta a situar a todos los miembros de una determinada sociedad en las condiciones de participación, en la competición de la vida o en la conquista de lo que es vitalmente más significativo, partiendo de posiciones iguales. Por su parte, la igualdad de resultados se corresponde con aquellas medidas que pretenden de manera directa satisfacer aspectos relevantes ${ }^{16}$.

\footnotetext{
14 VeGA, A. y López, M. (2011)

15 TUSET, P. (2011) p. 389.

${ }^{16}$ Bоввіо, N. (1993) р. 78.
} 
Barranco (2011) se ha pronunciado sobre esta línea y ha señalado que

la igualdad de oportunidades implica la adopción de medidas orientadas a eliminar los obstáculos que impiden que los individuos compitan en condiciones de igualdad mientras que la de resultados supone la adopción de medidas que directamente satisfacen necesidades o exigencias de personas y colectivos, pueden darse situaciones en las que precisamente una medida de este tipo implique la igualación de oportunidades ${ }^{17}$.

De acuerdo con la exposición de Barranco, la igualdad de oportunidades es el conjunto de medidas orientadas a evitar o compensar las desventajas que una persona tiene (en este caso, persona con discapacidad) para participar plenamente en la vida social, económica y cultural. En todo caso, la igualdad de oportunidades representa el uso de la igualdad en la práctica jurídica desde una óptica universal.

Establecida esta aproximación conceptual sobre la igualdad de oportunidades, no puede olvidarse, un concepto íntimamente ligado a esta cuestión: la discriminación, o dicho de otra manera, el fundamento y buena parte del contenido de la igualdad de oportunidades viene representado por la NO discriminación. Tal es así que, la Convención Internacional de Derechos de las Personas con Discapacidad define este término en su artículo 2(b) de la siguiente manera:

La lgualdad de oportunidades es la ausencia de toda discriminación, directa o indirecta, por motivo de o por razón de discapacidad, incluida cualquier distinción, exclusión o restricción que tenga el propósito o el efecto de obstaculizar o dejar sin efecto el reconocimiento, goce o ejercicio en igualdad de condiciones por las personas con discapacidad, de todos los derechos humanos y libertades fundamentales en los ámbitos político, económico, social, laboral, cultural, civil o de otro tipo. Asimismo, se entiende por igualdad de oportunidades la adopción de medidas de acción positiva.

En este sentido, puede observarse la relación tan estrecha que existe entre ambos términos (igualdad de oportunidades y no discriminación) lo que ha conllevado que la no discriminación se haya convertido en un derecho humano fundamental, relacionado con el proceso de reconocimiento de derechos, y la proyección de la igualdad como una constante en todas las Teorías de Derechos. Se trata pues, de un valor que ha quedado vinculado a la lucha contra la desigualdad. Siguiendo esta filosofía de pensamiento, afirma Céspedes (2007) que

${ }^{17}$ BARRANCO, M. C. (2011) p. 36. En esta misma obra advierte que:

es posible considerar situaciones en las que dos sujetos tengan las mismas oportunidades para competir, pero se produzcan circunstancias que hagan que de hecho, siempre ganen los sujetos que forman parte de un determinado grupo. Y ello es así porque en muchos casos, la reflexión sobre la igualdad se proyecta no ya sobre situaciones o practicas concretas sino más bien sobre estructuras sociales. 
este proceso de cambio y reconocimiento social se caracterizaría por dos aspectos: el respeto a la diversidad social y la conversión del ciudadano en sujeto activo de los procesos de transformación socialli.

Llegado este punto, conviene señalar también, la apreciación que Ribotta (2006) establece entre diferencia/desigualdad. A tal respecto afirma que

la diferencia, es algo connatural al hombre, a la misma existencia humana, revela la condición del hombre por naturaleza e influyen en redimir nuestra identidad. Sin embargo, la desigualdad es producto de la forma en la que el hombre organiza y distribuye los recursos y bienes sociales, así como, las posiciones que se derivan de ellos ${ }^{19}$.

Dicho esto, la desigualdad es un fenómeno histórico, cultural y jurídico que se convierte en un problema social cuando representa una amenaza o peligro para el mantenimiento de la igualdad, entendida esta como criterio de justicia y distribución. $Y$, es en esta escena, donde aparece el término discriminación, como noción que hace referencia a la diferenciación no justificada por basarse en situaciones sociales ajenas a la responsabilidad del sujeto y que suponen un perjuicio o desventaja.

Así pues, la No discriminación (prohibición de discriminación) pretende acabar con todas las desigualdades reprobables que niegan la dignidad social de los seres humanos. Esta prohibición se basa en identificar cuales son los criterios injustos o categorías que dan lugar a esta discriminación (raza, religión, sexo, discapacidad, etc.). Cualquier criterio resultante, habrá que justificarlo debida y especialmente, sin que ello suponga un trato discriminatorio. Como consecuencia de ello se ha venido distinguiendo dos tipos de discriminación. En opinión de Cabra de Luna (2011),

se entiende por discriminación directa, cuando una personas sea, haya sido o pudiera ser tratada de manera menos favorable que otra en una situación análoga y discriminación indirecta, cuando una disposición, criterio o práctica, aparentemente neutros pueda ocasionar una desventaja particular ${ }^{20}$.

En ocasiones, las personas con discapacidad, por tratarse de un sector más desfavorable, padecen formas de discriminación, entre las que pueden distinguirse entre otras, las siguientes: se discrimina desde el lenguaje (cuando se utilizan términos como tarado, mongólico, lisiado...); se discrimina con barreras arquitectónicas y comunicacionales que impiden la integración y el desempeño autónomo de las

\footnotetext{
${ }^{18}$ CÉspedes, A. (2007).

19 RiBOTA, S. (2006) p. 48.

${ }^{20}$ Cabra de Luna. M. A. (2011) p. 23.
} 
personas con discapacidad; se discrimina en el trabajo, incumpliendo normas legales que amparan el empleo de las personas con discapacidad; se discrimina en la educación; se discrimina en la salud incumpliendo las prestaciones que garantizan la rehabilitación y el acceso a la calidad de vida.

En cuanto a su regulación normativa, es crucial tener una legislación específica en materia de discapacidad ya que, las personas que la padecen y sus organizaciones, necesitan de estándares e instrumentos legales para exigir su cumplimento y evitar cualquier situación de discriminación, favoreciendo la creación de una sociedad accesible.

A nivel internacional, la Carta de los Derechos Fundamentales de la Unión Europea, prohíbe toda discriminación y reconoce el derecho de las personas con discapacidad de beneficiarse de medidas que favorezcan su integración ${ }^{21}$. El actual Tratado de Funcionamiento de la Unión Europea, (Lisboa 2007) recoge en su articulado numerosas referencias a la cuestión de discriminación para el conjunto de ciudadanos en general ${ }^{22}$. Más importante si cabe, es la Convención Internacional sobre los Derechos de las Personas con Discapacidad por ser el primer texto normativo específico en esta materia. Por esta razón, la no discriminación es un punto que está presente en todo el texto. En su precepto número 2, letras (c, $d$, e) establece la noción de discriminación atendiendo a los tipos o clases, que describía Cabra de Luna aunque es cierto, que el texto normativo amplia más su contenido como puede verse en el citado precepto $^{23}$ consagrado como principio general en su artículo

${ }^{21}$ Señala la Carta de Derechos Fundamentales de la Unión Europea en su artículo 21 : No discriminación

1. Se prohíbe toda discriminación, y en particular la ejercida por razón de sexo, raza, color, orígenes étnicos o sociales, características genéticas, lengua, religión o convicciones, opiniones políticas o de cualquier otro tipo, pertenencia a una minoría nacional, patrimonio, nacimiento, discapacidad, edad u orientación sexual.

En su artículo 26 sobre la Integración de las personas discapacitadas:

La Unión reconoce y respeta el derecho de las personas discapacitadas a beneficiarse de medidas que garanticen su autonomía, su integración social y profesional y su participación en la vida de la comunidad.

22 El Trato de Funcionamiento de la Unión Europea lo recoge en el artí́culo 10 de un modo general; la Segunda parte que tiene por título No discriminación y Ciudadanía (arts. 18-25); y por último el artículo 19 que hace mención expresa a la discapacidad.

${ }^{23}$ Según el art. 2 letras (c, d, e,) de la CIDPD, se distingue entre:

c) Discriminación directa: es la situación en que se encuentra una persona con discapacidad cuando es tratada de manera menos favorable que otra en situación análoga por motivo de o por razón de su discapacidad. d) Discriminación indirecta: existe cuando una disposición legal o reglamentaria, una cláusula convencional o contractual, un pacto individual, una decisión unilateral o un criterio o práctica, o bien un 
$3(b)^{24}$. El precepto que da título a este derecho, aparece regulado en el artículo $5^{25}$ sobre el cual, el profesor Giménez Gluck (2010) puntualiza que, en dicho artículo, no se utiliza el concepto de igualdad de trato, sino el de discriminación, prohibiendo ésta, obviamente, por motivos de discapacidad ${ }^{26}$.

A nivel estatal, en nuestra norma suprema, el artículo 49 CE está referido específicamente a las personas con discapacidad, (si bien su terminología no es la más adecuada pues emplea el término disminuidos físicos, sensoriales y psíquicos,) y consagra un deber positivo de acción del Estado en las políticas de previsión, tratamiento, rehabilitación e integración de las personas con discapacidad. En congruencia con los artículos 9.2 y 10 de la $C E$, el artículo 49 refiriéndose a las personas con discapacidad, ordena a los poderes públicos que presten la atención especializada que requieran y el amparo especial para el disfrute de sus derechos.

La norma de cabecera que abordó con mayor contenido esta materia fue la ya refundida Ley 51/2003, de 2 de diciembre, de Igualdad de Oportunidades, no Discriminación y Accesibilidad Universal de las personas con discapacidad (LIONDAU), que tuvo por título el reconocimiento de tal derecho. Esta ley estableció nuevos enfoques y estrategias derivados de los cambios operados en la concepción de la discapacidad, con expreso reconocimiento de las limitaciones sociales. Estas estrategias básicas fueron la lucha contra la discriminación y la accesibilidad universal. Posteriormente, la también refundida Ley 49/2007, de 26 de diciembre, por la que se establece el régimen de infracciones y sanciones en

entorno, producto o servicio, aparentemente neutros, puedan ocasionar una desventaja particular a una persona respecto de otras por motivo de o por razón de discapacidad, siempre que objetivamente no respondan a una finalidad legítima y que los medios para la consecución de esta finalidad no sean adecuados y necesarios. e) Discriminación por asociación: existe cuando una persona o grupo en que se integra es objeto de un trato discriminatorio debido a su relación con otra por motivo o por razón de discapacidad.

${ }^{24} \mathrm{El}$ art. 3 de la CIDPD reconoce como principio general en su apartado (b), "La no discriminación".

${ }^{25}$ El art. 5 de la CIDPD dice así: Igualdad y no discriminación:

1. Los Estados Partes reconocen que todas las personas son iguales ante la ley y en virtud de ella y que tienen derecho a igual protección legal y a beneficiarse de la ley en igual medida sin discriminación alguna. 2. Los Estados Partes prohibirán toda discriminación por motivos de discapacidad y garantizarán a todas las personas con discapacidad protección legal igual y efectiva contra la discriminación por cualquier motivo. 3. A fin de promover la igualdad y eliminar la discriminación, los Estados Partes adoptarán todas las medidas pertinentes para asegurar la realización de ajustes razonables. 4. No se considerarán discriminatorias, en virtud de la presente Convención, las medidas específicas que sean necesarias para acelerar o lograr la igualdad de hecho de las personas con discapacidad.

${ }^{26}$ GIMÉNeZ GLUCK, D. (2010). 
materia de igualdad de oportunidades, no discriminación y accesibilidad universal de las personas con discapacidad, supuso un renovado impulso a las políticas de equiparación de las personas con discapacidad. Pero la necesidad de nuevos cambios y la ratificación de la Convención por parte de los Estados miembros obligó a los mismos a establecer dentro de sus legislaciones internas un marco adecuado de respuestas a la discriminación que pudiera sufrir este colectivo, y no sólo de protección frente al trato discriminatorio directo, sino de acción positiva frente a las discriminaciones indirectas. En el caso de España, el Real Decreto Legislativo 1/2013, de 29 de noviembre, por el que se aprueba el Texto Refundido de la Ley General de Derechos de las Personas con Discapacidad y de su Inclusión Social, siguiendo las pautas marcadas por la Convención y de la misma forma, señala como objetivo principal (art. 1), la igualdad de oportunidades y la erradicación de cualquier forma de discriminación conforme a los artículos 9.2, 10 y 14 de la Constitución y asegura un elenco de medidas efectivas para acabar con cualquier forma desigualdad, tal como se cita entre los objetivos (art. 5).

El Título I avala el ejercicio de todos los derechos sociales reconocidos (sanidad, educación, vivienda, accesibilidad, trabajo, etc.) en igualdad de condiciones, sin que exista discriminación. El Título ll está dedicado a esta materia y tiene por rúbrica: "Igualdad de oportunidades y no discriminación", donde se recogen las medidas y el contenido de las mismas, sobre las cuales me ocuparé en el apartado siguiente. Por último, el Título III sobre las "Infracciones y Sanciones en materia de igualdad de oportunidades, no discriminación y accesibilidad universal de las personas con discapacidad" que como bien su nombre indica, recoge el régimen sancionador ante cualquier conducta discriminatoria. A pesar de disponer de un marco legislativo en materia de No discriminación hacia las personas con discapacidad, este se torna insuficiente por lo que es necesario adoptar decisiones políticas y medidas de regeneración y cambio, ya que la política pública de discapacidad no debe sufrir parálisis alguna. Para la consecución de este objetivo, el Foro Europeo de la Discapacidad (FED) instó a los Estados que adoptaran las medidas pertinentes sin que las acciones positivas que pudieran aprobarse generaran algún tipo de discriminación. El objetivo de tales acciones, será por tanto que, aquellas personas con discapacidad, víctimas de conductas discriminatorias generales, gocen de una igualdad de oportunidades real y no meramente formal. Además, el FED propugnó la elaboración de una directiva específica sobre la discapacidad que cubriera el acceso a los bienes y servicios ofertados incluido el acceso a la información y las nuevas tecnologías, edificios, transportes, etc. En esta línea se pronunció el Congreso Europeo de Personas con Discapacidad en 2002, donde se aprobó la Declaración de Madrid, la cual tuvo por lema: "No discriminación + Acción Positiva es igual a Inclusión social". 


\subsection{El principio de Inclusión Social}

Con motivo del año Internacional de la Discapacidad celebrado en 2003, la Declaración de Madrid, que preparó con esmero la celebración de este año, señaló que una sociedad que excluye a varios de sus miembros o grupos es una sociedad empobrecida. Así pues, se abogó por abandonar la concepción de una segregación innecesaria en cualquier esfera de la vida, y tomar conciencia de la inclusión de las personas con discapacidad dentro de la corriente mayoritaria ${ }^{27}$. Pero, ¿qqué se entiende por Integración/ Inclusión? Antes de hablar de medidas efectivas es necesario delimitar ambos conceptos. No existe una diferenciación clara y argumentada entre uno y otro y en la mayoría de las ocasiones se han utilizado como sinónimos o equivalentes.

Pérez Bueno (2010) señala que

el concepto de inclusión supera la vieja visión de la integración que entiende que aquellas personas que son diferentes tienen que ser aceptadas y toleradas por el sistema. Sin embargo, el concepto de inclusión, entiende que no es la persona la que tiene que ser aceptada como tal, sino que es el sistema el que ha de crear los moldes necesarios para poder adaptarse a las características diversas ${ }^{28}$.

Dicho con otras palabras, no se trata solo de transformar capacidades sino también de hacer transformar las condiciones sociales en los entornos en lo que viven.

La Ley General de los Derechos de las Personas con Discapacidad tiene por rúbrica en su título "de la Inclusión Social", lo recoge como objetivo fundamental en su artículo 1 y su definición en el artículo 2 apartado (j) diciendo así:

es el principio en virtud del cual la sociedad promueve valores compartidos orientados al bien común y a la cohesión social, permitiendo que todas las personas con discapacidad tengan las oportunidades y recursos necesarios para participar plenamente en la vida política, económica, social, educativa, laboral y cultural, y para disfrutar de unas condiciones de vida en igualdad con los demás.

La inclusión será una constante en todo el texto normativo extensible a cualquier ámbito de la vida (accesibilidad, educación, empleo, sanidad, vivienda, etc.). Por ello será necesario llevar a cabo un conjunto de acciones y medidas que mejoren las condiciones de las personas con discapacidad y que den lugar al diseño de

${ }^{27}$ http://www.ub.edu/integracio/docs/normativa/internacional/Declaracio-Madrid.pdf. Consultado día 26 Junio de 2015.

${ }^{28}$ Pérez Bueno, L. C. (2010). p. 34

Revista de Fomento Social 7//3-4 (2016) 
un mundo flexible para todos ${ }^{29}$. Años antes, el mismo Tribunal Constitucional se pronunció a este respecto y estableció que el reconocimiento de la igualdad de oportunidades y no discriminación de un colectivo como es el de las personas con discapacidad (como medida de inclusión), no es sólo un mero reconocimiento, sino el establecimiento de medidas, que facilite la plena inclusión de todas aquellas personas que se han encontrado en una situación jurídica de inferioridad ${ }^{30}$. A continuación, veremos qué medidas o acciones positivas hacen posible esta inclusión social.

\section{Medidas de acción positiva para la inclusión social}

Tal importancia tiene la adopción de acciones y medidas, que a nivel internacional, la misma Convención Internacional habla tanto del derecho a ser incluido en la comunidad (art. 19) como de la necesidad de adoptar medidas efectivas. Es la comunidad, de la que forman parte las personas con discapacidad, la que ha de garantizar su permanencia en la misma, respetando su diversidad, protegiendo sus derechos y adoptando las medidas que aseguren el ejercicio de los mismos en igualdad de condiciones ${ }^{31}$. A nivel estatal, la Ley general de los derechos de las personas con discapacidad, siguiendo las pautas marcadas por la Convención Internacional, recoge en su artículo 2 (g), la definición exacta de lo que se entiende por "medidas" y señala:

Medidas de acción positiva son aquellas de carácter específico consistentes en evitar o compensar las desventajas derivadas de la discapacidad y destinadas a acelerar o lograr la igualdad de hecho de las personas con discapacidad y su participación plena en los ámbitos de la vida política, económica, social, educativa, laboral y cultural, atendiendo a los diferentes tipos y grados de discapacidad.

${ }^{29}$ Señala el art. 49 de la CE:

Los poderes públicos realizarán una política de previsión, tratamiento, rehabilitación e in tegración de los disminuidos físicos, sensoriales y psíquicos a los que prestarán la atención especializada que requieran y los ampararán especialmente para el disfrute de los derechos que este Título otorga a todos los ciudadanos.

${ }^{30}$ STC 3/1993 de 14 enero; Ponente, Excmo. Sr. Magistrado don Carlos de la Vega Benayas.

${ }^{31}$ El art. 19 de la CIDPD señala:

Los Estados Partes en la presente Convención reconocen el derecho en igualdad de condiciones de todas las personas con discapacidad a vivir en la comunidad, con opciones iguales a las de las demás, y adoptarán medidas efectivas y pertinentes para facilitar el pleno goce de este derecho por las personas con discapacidad y su plena inclusión y participación en la comunidad. 
De todas las medidas que señala la ley, tanto a nivel internacional como estatal en materia de inclusión, resaltaré aquellas que considero esenciales para la inclusión real y efectiva de las personas con discapacidad, pues cualquier política de inclusión pasa por el esfuerzo previo de garantizar la igualad de oportunidades y tras ello, otros recursos materiales/medidas como son: la Accesibilidad, la Educación y el Empleo ${ }^{32}$.

\section{I.Accesibilidad Universal}

¿Qué se entiende por Accesibilidad Universal? La Accesibilidad Universal consiste en planear, proyectar, construir, rehabilitar y conservar el entorno teniendo en cuenta las necesidades y los requerimientos de cualquier persona sea cual sea su edad, circunstancia o capacidad. Un entorno acorde con los principios de la Accesibilidad Universal (AU) será un entorno que facilite el desenvolvimiento y uso del mismo por cualquier persona, desde características como la comodidad, seguridad y autonomía personal. La Accesibilidad Universal abarca los ámbitos de la edificación, las vías y espacios públicos, parques y jardines, entorno natural, transporte, señalización, comunicación y prestación de servicios. Constituye un tema de presente, en el proceso de normalización y plena ciudadanía de las personas con discapacidad y debería ser, el eje de toda política pública, de toda acción e intervención, pública y privada. Según Pérez Bueno (2011),

la accesibilidad es una cuestión de derechos civiles, por lo que la ausencia de accesibilidad ha de considerarse como una violación de estos derechos, un acto antijurídico, un trato desigual discriminatorio prohibido por la Ley y por tanto perseguida ${ }^{33}$.

La Accesibilidad ha sido en España, el gran fracaso de las políticas públicas de discapacidad de estos últimos 25 años convirtiéndose en el gran tema olvidado. Pioneras en esta materia, fue la ya refundida Ley de Integración Social del Minusválido (LISMI) que contenía aspectos de accesibilidad, (artículos 54 y siguientes) referidos a la movilidad y barreras arquitectónicas y posteriormente, tal como he referido anteriormente, la LIONDAU (ya refundida) que introdujo el enfoque de la accesibilidad como una cuestión de derechos y el carácter universal de la misma. Además otorgó al Estado, atribuciones y competencias para regular unas condiciones básicas de igualdad y no discriminación, de obligado cumplimiento en todo el territorio nacional. La accesibilidad no es cosa sólo de las Comunidades

\footnotetext{
32 La LGDPD reconoce como principales medias para la inclusión, las siguientes: la accesibilidad, la educación y el empleo.

33 Pérez Bueno, L. C. (2011) pp. 235-245.
}

Revista de Fomento Social 7//3-4 (2016) 
Autónomas, sino que el Estado, como garante último de la igualdad de todos los ciudadanos, se reserva competencias para regular normas básicas que vinculan a todos los poderes y a todas las instancias públicas y privadas.

Con estos antecedentes, hoy en día, esta materia ha experimentado un giro sorprendente, a partir del entendimiento de la discapacidad (ya iniciado por la LIONDAU) como una cuestión de derechos humanos, de derechos fundamentales, de los que son titulares las personas con discapacidad. Este cambio de concepto y perspectiva, es especialmente visible en el artículo 2 (k) de la LGDPD en lo referido a la accesibilidad universal, que la define como

la condición que han de reunir los entornos, productos, bienes y servicios, a disposición del público, para que puedan ser usados por las personas con discapacidad con normalidad y regularidad. Presupone la estrategia de "diseño universal o diseño para todas las personas", y se entiende sin perjuicio de los ajustes razonables que deban adoptarse.

De la definición aportada, De Asís (2013) realiza una precisión importante a tener en cuenta. Si se observa el precepto, en ningún momento habla de la accesibilidad como un derecho, sino como una condición. De igual manera se refiere a ella en el artículo 22 LGDPD, que vuelve a entenderla como una condición cuando trata el derecho a vivir de formar independiente y a participar plenamente en todos los aspectos de la vida. Además, continúa diciendo que el artículo 3 LGDPD habla de ella como principio (no como derecho) ${ }^{34}$. Si bien es cierto que se habla de la accesibilidad como condición en su definición, discrepo de la aportación doctrinal realizada por De Asís, por dos razones fundamentales. En primer lugar, porque en su sentido más amplio se ha tratado como una cuestión de derechos humanos. Así lo trató de reflejar la Convención y la LGDPD, y en segundo lugar, la accesibilidad aparece recogida en Capítulo V, dedicado a los derechos (en concreto dentro del derecho a la vida Independiente) y numerosos preceptos se refieren a ella como exigibilidad y por tanto si es exigible es derecho ${ }^{35}$. En mi opinión es un defecto de nomenclatura y no sólo hay que quedarse con la terminología aplicada sino con el sentido general que trata de dársele.

Secundando lo establecido en la Convención Internacional, la Ley General de los Derechos de las Personas con Discapacidad contiene una serie de normas en las que se determinan las condiciones básicas de accesibilidad las cuales establecen

${ }^{34}$ De Asís Rolg, R. (2013) p. 5.

35 Véase en LGPD como numerosos preceptos aluden a la accesibilidad como exigibilidad. art. 23.2

(a), art. 24.1, art. 25.1, art. 27.1, art. 28.1, art. 29.4, art. 81.3 (b) en materia de infracciones. 
unos mismos niveles de igualdad de oportunidades a todos los ciudadanos con discapacidad y medidas concretas para prevenir o suprimir discriminaciones y compensar desventajas o dificultades (art. 9.2). Con ello, la ley da un nuevo enfoque al concepto de accesibilidad. No solo supera el concepto en el sentido de barreras arquitectónicas (entendidas desde un punto de vista urbanístico como tradicionalmente se ha venido entiendo, conceptos anticuados como el de eliminación de barreras, adaptación, acondicionamiento) sino que además extrapola dicho término a otros ámbitos tales como la comunicación, información, tecnología, etc. ${ }^{36}$

Prueba de esta nueva realidad y en virtud del principio de transversalidad de las políticas de discapacidad, el artículo 5 de la LGDPD, se refiere a la accesibilidad de carácter universal aplicada a otros ámbitos como pueden ser: telecomunicación y sociedad de la información, espacios públicos urbanizados, infraestructuras y edificación, transportes, bienes y servicios a disposición del público, relaciones con las administraciones públicas, administración de justicia, patrimonio cultural de conformidad con lo previsto en la legislación del patrimonio histórico y empleo.

Para el desarrollo de lo establecido, el legislador ha contemplado la regulación de disposiciones sobre accesibilidad de los edificios y entornos, de los instrumentos, equipos y tecnologías, y de los bienes y productos utilizados en el sector o área; también observa condiciones más favorables en el acceso, participación y utilización de los recursos, los apoyos complementarios económicos, tecnológicos o especializados. Además de la legislación indicada, se incluyen planes de ejecución gradual diseñados, teniendo en cuenta los diferentes tipos y grados de discapacidad. Toda esta legislación y planes, conforman la regulación de esta materia ${ }^{37}$.

${ }^{36}$ Las medidas que recoge el art. 9.2 de la CIDPD son:

Los Estados Partes también adoptarán las medidas pertinentes para: a) Desarrollar, promulgar y supervisar la aplicación de normas mínimas y directrices sobre la accesibilidad de las instalaciones y los servicios abiertos al público o de uso público; b) Asegurar que las entidades privadas que proporcionan instalaciones y servicios abiertos al público o de uso público tengan en cuenta todos los aspectos de su accesibilidad para las personas con discapacidad; c) Ofrecer formación a todas las personas involucradas en los problemas de accesibilidad a que se enfrentan las personas con discapacidad; d) Dotar a los edificios y otras instalaciones abiertas al público de señalización en Braille y en formatos de fácil lectura y comprensión; e) Ofrecer formas de asistencia humana o animal e intermediarios, incluidos guías, lectores e intérpretes profesionales de la lengua de señas, para facilitar el acceso a edificios y otras instalaciones abiertas al público; f) Promover otras formas adecuadas de asistencia y apoyo a las personas con discapacidad para asegurar su acceso a la información; g) Promover el acceso de las personas con discapacidad a los nuevos sistemas y tecnologías de la información y las comunicaciones, incluida Internet; $h$ ) Promover el diseño, el desarrollo, la producción y la distribución de sistemas y tecnologías de la información y las comunicaciones accesibles en una etapa temprana, a fin de que estos sistemas y tecnologías sean accesibles al menor coste.

${ }^{37}$ En el siguiente enlace http://www.msssi.gob.es/ssi/discapacidad puede consultarse todo el conjunto de disposiciones normativas que configuran esta disciplina en cada uno de los ámbitos referidos. 


\subsection{Educación Inclusiva}

En el ámbito de la educación, el concepto de inclusión hace referencia al modo en el que la escuela, debe dar respuesta a la diversidad. Tratar educativamente las diferencias abre el camino hacia la igualdad de oportunidades para las personas con discapacidad. La educación inclusiva es un término de reciente uso en la práctica educativa que trata de modificar el sistema escolar para que responda a las necesidades de todos los alumnos y no sean estos, quienes se deban de adaptar al sistema para integrarse en él. En este sentido, es necesaria la personalización de la educación como medida positiva no sólo para estudiantes con discapacidad, sino en general para todas aquellas personas que por alguna razón encuentren dificultad en su proceso de integración o adaptación en la escuela, porque en ocasiones cuando llegan al aula, muchos alumnos abandonan los estudios por encontrarse con un sistema inoperativo y poco flexible.

Villalobos y Zalakain (2010) reconocen la distinción entre integración e inclusión educativa, aportando a la doctrina una mayor precisión. A saber:

1. La integración se basa en la "normalización" de la vida del alumnado con necesidades educativas especiales. La inclusión plantea el reconocimiento y valoración de la diversidad como una realidad y como un derecho humano, esto hace que sus objetivos sean prioritarios siempre. Desde la perspectiva de la inclusión la heterogeneidad es entendida como lo normal, de modo que la postura inclusiva se dirige a todo el alumnado y a todas las personas en general.

2. La integración se centra en el alumnado con necesidades educativas especiales, para los que se habilitan determinados apoyos, recursos y profesionales mientras que la inclusión se basa en un modelo sociocomunitario donde el centro educativo y la comunidad escolar están fuertemente implicados, lo que conduce a la mejora de la calidad educativa en su conjunto y para todo el alumnado. Se trata de una organización inclusiva en sí misma, en la que se considera que todos los miembros están capacitados para atender la diversidad.

3. La integración propone adaptaciones curriculares como medidas de superación de las diferencias del alumnado con necesidades especiales; la inclusión propone un currículo inclusivo común para todo el alumnado, en el que implícitamente se vayan incorporando esas adaptaciones. El currículo no debe entenderse como la posibilidad de que cada alumno aprenda cosas diferentes, sino más bien que las aprenda de diferente manera.

4. La integración supone conceptualmente la existencia de una anterior separación o segregación. Una parte de la población escolar se encuentra fuera del sistema educacional regular y debe ser integrada en éste. En este proceso el sistema permanece más o menos intacto, mientras que quienes deben integrarse tienen la tarea de adaptarse a él. La inclusión supone un sistema único para todos lo que implica diseñar el currículo, las metodologías empleadas, los sistemas de enseñanza, la infraestructura y las estructuras 
organizacionales del sistema educacional de tal modo que se adapten a la diversidad de la totalidad de la población escolar que el sistema atiende ${ }^{38}$.

En cuanto al marco jurídico que lo regula, la Educación como derecho de los derechos aparece reconocida legalmente como tal:

A nivel internacional: La CIDPD lo reconoce en su artículo 24 que establece:

1. Los Estados Partes reconocen el derecho de las personas con discapacidad a la educación. 2.a) Las personas con discapacidad no queden excluidas del sistema general de educación por motivos de discapacidad, y que los niños y las niñas con discapacidad no queden excluidos de la enseñanza primaria gratuita y obligatoria ni de la enseñanza secundaria por motivos de discapacidad.

A nivel estatal, se distingue: por un lado, en nuestra Carta Magna que reconoce este derecho, en su art. 27.1 señalando que: "Todos tienen el derecho a la educación". Y por otro, en la Ley General de los Derechos de las Personas con Discapacidad (arts. 18-21) concretamente, el artículo 18.1 señala: "Las personas con discapacidad tienen derecho a una educación inclusiva, de calidad y gratuita, en igualdad de condiciones con las demás".

A nivel autonómico: La Ley de Atención a las Personas con Discapacidad de Andalucía dedica su Título III, denominado "De atención a las necesidades educativas especiales" (arts. 14-18). En este sentido, el artículo 14 dispone:

La presente Ley reconoce a las personas con una discapacidad de tipo físico, psíquico o sensorial, en sus diversos grados y manifestaciones, el derecho a recibir la atención educativa específica que por sus necesidades educativas especiales requieran, tan pronto como se adviertan circunstancias que aconsejen tal atención o se detecte riesgo de aparición de la discapacidad, con el fin de garantizar su derecho a la educación y al desarrollo de un proceso educativo adecuado y asistido con los complementos y apoyos necesarios.

Desde finales de los años ochenta, el movimiento materializado por padres, profesores, y las propias personas con discapacidad, luchan contra una educación especial por una educación inclusiva. Este movimiento partía de la idea de una educación diversa del alumnado comprometida en crear nuevas formas. El reconocimiento de este derecho se convierte en realidad práctica, en primer lugar con la Ley Orgánica 1/1990, de 3 de octubre, de Ordenación General del Sistema Educativo (LOGSE) y posteriormente, con mayor precisión, con la Ley Orgánica

38 VILLALOBOS, E. y ZALAKAIN, J. (2010) p. 32. 
2/2006, de 3 mayo, de Educación (LOE) ${ }^{39}$, que se hace eco de este principio, aunque según señala Martínez Abellán (2010) con algunos matices:

"-Compromiso social de los centros con la educación realizando una escolarización sin exclusiones y respondiendo a los principios de calidad y equidad.

- Dar una respuesta trazada en la normativa y desarrollada desde el principio de autonomía de los centros.

- Medidas que respondan a las necesidades de todo el alumnado en el marco de un sistema educativo mediante el principio de inclusión ${ }^{40}$.

Recientemente, la Ley de Educación modificada considerablemente en algunos de su preceptos por la Ley Orgánica 8/2013, de 9 de diciembre, para la mejora de la calidad educativa (LOMCE) ${ }^{41}$ y, en vigor desde el curso escolar 2015/2016, añade la accesibilidad universal, la igualdad de oportunidades y la educación inclusiva con especial atención a las personas con discapacidad ${ }^{42}$. El Preámbulo del precitado texto dice así:

con el fin de garantizar la equidad, aborda los grupos de alumnos que requieren una atención educativa diferente a la ordinaria por presentar alguna necesidad específica de apoyo educativo y establece los recursos precisos para acometer esta tarea con el objetivo de lograr su plena inclusión e integración. Se incluye concretamente en este título: 1) Alumnos que requieren determinados apoyos y atenciones específicas derivadas de circunstancias sociales, de discapacidad física, psíquica o sensorial o que manifiesten trastornos graves de conducta. El sistema educativo español ha realizado grandes avances en este ámbito en las últimas décadas, que resulta necesario continuar impulsando. 2) Alumnos con altas capacidades intelectuales. 3) Alumnos que se han integrado tarde en el sistema educativo español.

Pero además, entre sus principales fines, señala el artículo 2 (b:)

${ }^{39}$ BOE núm. 106, de 4 de mayo de 2006.

40 Martínez Abellán, R (2010) p. 152.

${ }^{41}$ BOE núm. 295, de 10 diciembre de 2013.

${ }^{42}$ Artículo único. Modificación de la Ley Orgánica 2/2006, de 3 de mayo, de Educación. La Ley Orgánica 2/2006, de 3 de mayo, de Educación, se modifica en los siguientes términos: Uno. Se modifica la redacción de los párrafos b), k) y l) y se añaden nuevos párrafos $\mathrm{h}$ bis) y q) al artículo 1 en los siguientes términos:

b) La equidad, que garantice la igualdad de oportunidades para el pleno desarrollo de la personalidad a través de la educación, la inclusión educativa, la igualdad de derechos y oportunidades que ayuden a superar cualquier discriminación y la accesibilidad universal a la educación, y que actúe como elemento compensador de las desigualdades personales, culturales, económicas y sociales, con especial atención a las que se deriven de cualquier tipo de discapacidad. 
la educación en el respeto de los derechos y libertades fundamentales, en la igualdad de derechos y oportunidades entre hombres y mujeres y en la igualdad de trato y no discriminación de las personas con discapacidad.

Como novedad legislativa, añade, en virtud del artículo 59, al Título II, Capítulo I (arts. 71-79), una cuarta sección, denominada "alumnado con dificultades especificas en el aprendizaje", una medida más que viene a completar al resto de las que ya aparecían recogidas en este Título. El artículo 73 de la LOE, ofrece el concepto de alumno con necesidades específicas, y en el artículo 75 de la misma, la necesidad de garantizar la inclusión social y laboral de las personas con discapacidad ${ }^{43}$. Del mismo modo, se fomenta en igualdad de oportunidades que el resto, el acceso a la Formación Profesional (art. 40 modificado por art. 33 LOMCE), y a la Universidad (art. 38 modificado por art. 31 de la LOMCE). Por último, entre los recursos previstos para la mejora del proceso de enseñanza /aprendizaje se identifican en esta ley medidas de atención a la diversidad tales como: ratio, programas de refuerzo, apoyo, servicios o profesionales especializados en orientación.

Analizados el conjunto de textos legales, desde el orden internacional hasta el autonómico, todos ellos, reconocen que la Educación de las personas con discapacidad es un derecho exigible y medio para asegurar su igualdad e inclusión efectiva. Según señala ARNAIZ, el Derecho y la Educación son las herramientas que hacen posible esta realidad. "Es imprescindible educar y legislar en el marco de un modelo social y diverso de la discapacidad". Este nuevo modelo requiere de una educación de calidad, no discriminatoria, participativa y que asuma la heterogeneidad como factor de enriquecimiento ${ }^{44}$. Dicho en otras palabras, hacer de la discapacidad una "normalización", no una causa de distinción. Educar bajo el concepto de que las personas con discapacidad son diferentes/diversas pero no por ello, desiguales al resto. Si no se educa desde esta perspectiva, siempre

${ }^{43}$ Señala el art. 73:

Se entiende por alumnado que presenta necesidades educativas especiales, aquel que requiera, por un periodo de su escolarización o a lo largo de toda ella, determinados apoyos y atenciones educativas específicas derivadas de discapacidad o trastornos graves de conducta.

Para la inclusión laboral y social, el art. 75 establece:

1) Con la finalidad de facilitar la integración social y laboral del alumnado con necesidades educativas especiales que no pueda conseguir los objetivos de la educación obligatoria, las Administraciones públicas fomentarán ofertas formativas adaptadas a sus necesidades específicas. 2) Las Administraciones educativas establecerán una reserva de plazas en las enseñanzas de formación profesional para el alumnado con discapacidad.

${ }^{44}$ Arnalz, P. (2007) pp. 35-40.

Revista de Fomento Social 7//3-4 (2016) 
existirá discriminación. La educación contribuye a mejorar la vida y es una pieza clave para acabar con las desigualdades más arraigadas en la sociedad porque la educación promueve la libertad y la autonomía personal generando importantes beneficios para el desarrollo personal.

\subsection{Empleo}

La última medida tratar y no menos importante que las dos anteriores es el empleo, medida que garantiza sin lugar a dudas, la igualdad de oportunidades de todas las personas y contribuye decisivamente en la participación plena de los ciudadanos en la vida económica, cultural y social, así como a su desarrollo personal y por tanto su inclusión en la vida comunitaria. El empleo es un elemento esencial para las personas con discapacidad, especialmente aquéllas que presentan una discapacidad severa. Uno de los objetivos básicos de la política de empleo de trabajadores con discapacidad es su integración en el sistema de trabajo. En España, no es esta una cuestión de solidaridad social y de sentido común, sino una exigencia constitucional recogida en el artículo $39 \mathrm{CE}$, tal cual ya he referido con anterioridad. ${ }^{45}$

Durante los últimos años, nuestro país ha potenciado las políticas e iniciativas dirigidas a facilitar un empleo normalizado de las personas con discapacidad. Esto ha supuesto por un lado la promoción de nuevas estructuras laborales e incentivos a las empresas para contraten personas con discapacidad. Por otro lado, se ha dado cada vez más importancia a proveer los apoyos humanos y materiales necesarios para la inserción laboral de las personas con discapacidad en los diferentes puestos de trabajo. El acceso a un determinado puesto de trabajo o empleo está asociado a la accesibilidad y como no, a la educación/formación recibida. Es necesario que la formación de las personas con discapacidad se diseñe teniendo en cuenta las necesidades reales del mercado laboral y que se les facilite un mayor abanico de posibilidades para conseguir una mayor pericia laboral que sea real y efectiva. Por último, es preciso que los empresarios ganen experiencia empleando a más personas con discapacidad, que constaten el valor añadido de la diversidad en sus plantillas y que perciban a las personas con discapacidad como trabajadores productivos.

Un avance significativo en materia de empleo para las personas con discapacidad fue la Ley 43/2006, de 29 de diciembre, para la mejora del crecimiento y del empleo, la cual, establece en su Exposición de Motivos que

${ }^{45}$ Según señala el art. 39.1 CE: "Los poderes públicos aseguran la protección social, económica y jurídica de la familia". 
entre los objetivos principales de esta Ley, figuran la reducida tasa de ocupación y actividad de las mujeres españolas, el que la tasa de paro todavía supere ligeramente a la media de la Unión Europea, siendo especialmente elevada en el caso de los jóvenes, las mujeres y las personas con discapacidad, la persistencia de segmentaciones entre contratos temporales e indefinidos y, sobre todo, la elevada tasa de temporalidad, la más alta de la Unión Europea, y por encima del doble de la media de ésta. En relación con la tasa de temporalidad, además son relevantes los niveles particularmente elevados de las correspondientes a los jóvenes, las mujeres, los trabajadores menos cualificados y de menores salarios y los trabajadores con discapacidad. ${ }^{46}$

Esta ley es muestra palpable de que el Legislador tiene al menos consciencia del gran desagravio que sufren las personas con discapacidad en el ámbito laboral. Entre las medidas adoptadas como posibles soluciones para tan complejo problema, se realizó todo un itinerario de acceso al empleo para personas con discapacidad en función de las capacidades de las personas. Siguiendo la línea trazada, la Ley General de los Derechos de las Personas con Discapacidad, distingue como regímenes laborales: el empleo ordinario (Sección $2^{a}$ del Capítulo VI del Título l) y el empleo protegido (Sección $3^{\text {a }}$ del Capítulo VI del Título I) y empleo autónomo:

En lo que se refiere al Empleo Ordinario o también conocido como "empleo normalizado" engloba el trabajo en empresas y en las administraciones públicas incluyendo los servicios de empleo con apoyo (art. 37.2 LGPD). Se concibe como el trabajo en empresas, aquel donde el porcentaje mayoritario de trabajadores está compuesto por personas sin discapacidad. Las empresas que ocupen 50 o más trabajadores están obligadas a emplear a un número determinado de personas con discapacidad, no inferior al 2 por 100 (art. 42 LGPD). Veamos a continuación los siguientes datos:

Porcentaje de asalariados con discapacidad respecto al total de asalariados que cotizan a la Seguridad Social en empresas ordinarias del sector privado:

\begin{tabular}{|l|l|}
\hline Total de asalariados & $1,8 \%$ \\
\hline Empresas de menos de 50 trabajadores & $1,2 \%$ \\
\hline Empresas de 50 o más trabajadores & $2,3 \%$ \\
\hline
\end{tabular}

Fuente: Instituto Nacional de Estadística 2014

${ }^{46}$ BOE núm. 312, de 30 de diciembre. 
En cuanto al empleo público, Jiménez Aparicio (2009) resalta que

existe una nueva concepción de la contratación pública, que ha implicado el entendimiento de la misma como un instrumento para llevar a cabo políticas sociales, integrando así el conjunto de políticas perseguidas por los poderes públicos ${ }^{47}$.

Partiendo de esta concepción, las Administraciones Públicas están sujetas a la obligación de reserva de puesto de trabajo, en sus dos modalidades:

1) Cuota de reserva para el acceso a la Función Pública, regulado en el Real Decreto Legislativo 5/2015, de 30 de octubre, por el que se aprueba el Texto Refundido de la Ley del Estatuto Básico del Empleado Público) ${ }^{48}$. Concretamente, establece que en las Ofertas de Empleo Público se reservará un cupo no inferior al 7\% (antes era el $5 \%$ ) de las vacantes para ser cubiertas entre personas con discapacidad, siempre que superen los procesos selectivos y acrediten su discapacidad y la compatibilidad con el desempeño de las tareas, de modo que progresivamente se alcance el $2 \%$ de los efectivos totales en cada Administración Pública. Del citado 7\% de reserva, al menos un $2 \%$ (puede ser más del $2 \%$ ), irá destinado a personas que acrediten discapacidad intelectual así lo señala su art. 59.

2) Cuota de reserva para el acceso a la contratación pública (empresas públicas), regulado en el RD Legislativo 3/201 1 de 14 de noviembre por el que se aprueba el Texto Refundió de la Ley de Contratos del Sector Público ${ }^{49}$ en, señalando en su Disposición Adicional Cuarta, la obligación de contar con un 2 por 100 de trabajadores con discapacidad o adoptar las medidas alternativas correspondientes. Puede observarse que los cupos de reserva establecidos, son escasos para el nivel de población con discapacidad que existe hoy en día y más aún si tenemos en cuenta las personas que pueden sufrirla por una circunstancia sobrevenida.

Por último, en la modalidad del empleo ordinario, destacan los Servicios de Empleo con Apoyo que tuvieron en sus inicios, un carácter de rehabilitación ocupacional y como común denominador, la formación de los trabajadores con discapacidad en las tareas laborales antes de su inserción en los correspondientes puestos de trabajo. Tras una considerable evolución, actualmente, pueden definirse como

\footnotetext{
47 Jiménez Aparicio, E. (2009) p. 133.

${ }^{48}$ BOE núm. 261, de 31 de octubre.

${ }^{49}$ BOE núm. 276, de 16 de noviembre.
} 
el conjunto de actividades de orientación y acompañamiento individualizado especializados en el propio puesto de trabajo, que tienen por objeto facilitar la adaptación social y laboral de personas trabajadoras con discapacidad con especiales dificultades de inclusión laboral en empresas del mercado ordinario de trabajo en condiciones similares al resto de trabajadores que desempañan puestos equivalentes (art. 41 LGPD) ${ }^{50}$.

Según señala Becerra Traver (2012), el empleo con apoyo ha servido para proporcionar trabajo a cerca de 3.000 personas en toda España ${ }^{51}$.

La segunda modalidad de empleo recogida en nuestra legislación, es el Empleo Protegido regulado en la Ley General de los Derechos (arts. 43-45) donde se detallan las siguientes clases:

1.- Los Centros Especiales de Empleo (CEE) los cuales nacen como fórmula de empleo para personas con discapacidad. Son empresas promovidas principalmente por asociaciones de personas con discapacidad y/o sus familiares, sin perivicio de que cualquier persona física o jurídica pueda constituir uno, siempre con sujeción a normas legales, reglamentarias y convencionales que regulen las condiciones de trabajo. Así lo estableció el Real Decreto 2273/1985, de 4 de diciembre, por el que se aprueba el Reglamento de los Centros Especiales de Empleo definidos como

centros públicos o privados cuyo objetivo principal es el de realizar un trabajo productivo de bienes y servicios, así como, asegurar una remuneración para los trabajadores y la integración del mayor número de personas con discapacidad al mercado ordinario" (art. 43.1 LGPD).

El objetivo principal de estos centros es la integración laboral y por tanto social de personas con discapacidad. Para obtener la calificación de Centro Especial de Empleo, las empresas deben contar en su plantilla con un mínimo del 70 por 100 de trabajadores con discapacidad y solicitar la correspondiente calificación a la administración competente (art. 43.2 LGPD).

\footnotetext{
${ }^{50}$ Las principales características de este tipo de empleo son: 1. Colocaciones individualizadas en empresas normalizadas o convencionales. 2. Contratos laborales y salarios justos. 3. Acompañamiento del preparador laboral y desarrollo de apoyos naturales. 4 . Instrucción sistemática y formación dentro del puesto de trabajo. 5. Retirada progresiva del preparador laboral. 6 . Apoyo técnico y seguimiento durante la vida laboral de la persona. 7 . El empleo con apoyo sirve para las personas con discapacidad o en riesgo de exclusión que nunca han tenido acceso al mercado laboral o que no han sido capaces de mantener un empleo.
}

${ }^{51}$ Becerra Traver, M. T. (2012) pp. 9-15. 
Hablar de los CEE, como en cualquier otro sector empresarial, es hablar de multiplicidad de características y modelos de gestión, es un sector, que además está en continua adaptación con el entorno y no puede establecerse generalidades ni de sector ni de actividad, ni de tamaño. Así, existen muy diferentes tamaños (desde un trabajador a más de mil). Desarrollan diversas actividades $y$, si bien nacen ligados a la subcontratación industrial, han ido abriéndose a nuevos mercados que les han llevado tanto a la producción de bienes, como a la cada vez más presente prestación de servicios, tanto en sectores tradicionales, como en aquellos sectores más punteros. De hecho, en algunos sectores, como lavandería Industrial, son líderes absolutos del sector. Entre aquellas actividades más conocidas encontramos: limpieza, telemarketing, montajes industriales, manipulados, tratamiento de datos, textil, imprenta, jardinería. Y también presentes en actividades menos conocidas: gestión integral de residuos hospitalarios, consultoría de dirección y gestión empresarial, desarrollo de proyectos de accesibilidad, gestión integral y desarrollos tecnológicos, correduría de seguros y servicios de logística.

2.- Los Enclaves Laborales. Es la otra modalidad de empleo protegido regulada en el artículo 46 LGPD, el cual viene a señalar que el objetivo final de los mismos es "facilitar la transición desde el empleo protegido al empleo ordinario". Su desarrollo normativa se establece en RD 290/2004, de 20 de febrero, por el que se regulan los enclaves laborales como medida de fomento del empleo de las personas con discapacidad. La definición de este recurso aparece recogida en el artículo 1 del citado RD que viene a establecer:

Se entiende por enclave laboral, el contrato entre una empresa del mercado ordinario de trabajo, llamada empresa colaboradora, y un Centro Especial de Empleo (CEE) para la realización de obras o servicios que guarden relación directa con la actividad principal de aquélla y para cuya realización un grupo de trabajadores con discapacidad del Centro Especial de Empleo se desplaza temporalmente al centro de trabajo de la empresa colaboradora.

Es una fórmula de relación comercial entre empresa ordinaria y CEE. Se trata de un instrumento para la creación de empleo para personas con discapacidad y su posible incorporación al mercado abierto. La dirección y organización del trabajo corresponde al centro especial de empleo, con el que el trabajador mantendrá plenamente su relación laboral de carácter especial, durante la vigencia de dicho enclave. Este tipo de empleo fomenta el desarrollo de una actividad productiva por un equipo profesional de un CEE en las instalaciones de otra empresa ${ }^{52}$.

52 BOE núm. 45, de 21 de febrero. En su art. 2 aparecen regulados, de forma específica, los objetivos a los que están orientados los enclaves laborales. 
Para concluir con las modalidades de empleo, resta señalar el Empleo Autónomo (art. 47 LGPD), entendido como

aquel que es generado por el propio trabajador con discapacidad constituyéndose como autónomo o creando una empresa, tenga o no otros trabajadores bajo su dependencia.

La Administración General ha recogido entre sus medidas, aquellas destinadas al fomento del autoempleo, que financian proyectos empresariales, proyectos de autoempleo de trabajadores por cuenta propia y conceden subvenciones para la constitución de cooperativas de trabajo. Entre estas medidas se pueden distinguir:

1. Pago único de la prestación por desempleo como medida del empleo de trabajadores autónomos con discapacidad que será compatible con otro tipo de ayudas de promoción del trabajo que puedan obtenerse.

2. Abono de las cuotas a la Seguridad Social de los trabajadores que haya percibido la prestación por desempleo en su modalidad de pago único por la cuantía total que tuviera derecho.

3. Ayudas al establecimiento y mantenimiento como trabajador autónomo.

En esta línea, la medida más reciente, en el ámbito de la discapacidad, es el Convenio Especial para personas con discapacidad que tengan especiales dificultades de inserción laboral cuya regulación aparece en el Real. Decreto 156/2013, de 1 de marzo, por el que se regula la suscripción de convenio especial por las personas con discapacidad que tengan especiales dificultades de inserción laboral ${ }^{53}$. Actualmente, está en vigor la Estrategia de Activación para el Empleo (EEAE) 2014-2016 aprobada por el Real Decreto 751/2014, de 5 de septiembre, por el que se aprueba la Estrategia Española de Activación para el Empleo 2014-2016 ${ }^{54}$. Esta nuevo plan se articula en torno a seis ejes (orientación, formación, oportunidades de empleo, igualdad de oportunidades en el acceso al empleo, emprendimiento y mejora del marco institucional del Sistema Nacional de Empleo) previamente consensuados entre el Servicio Público de Empleo Estatal y las Comunidades Autónomas. De todas las medidas y estrategias expuestas en

\footnotetext{
${ }^{53}$ BOE núm. 53, de 2 de marzo.

${ }^{54}$ BOE núm. 231, de 23 de septiembre. Véase en este RD, todo el contenido de la Estrategia vigente, marco jurídico, principios de actuación, instrumentos, régimen presupuestario y seguimiento. De este último aparatado adolecía la anterior Estrategia (2012-2014). Es una de las principales novedades
} introducidas. 
materia de empleo, es responsable la Secretaría Técnica del Ministerio de Trabajo y Seguridad Social, a través del Servicio Público de Empleo Estatal (SEPE) que asumirá las competencias de planificación, dirección, control e inspección de las actividades para el cumplimiento de sus fines, al que se encomienda la ordenación, desarrollo y seguimiento de los programas y medidas de la política de empleo. Por último, veamos datos reales sobre la realidad más actual de las personas con discapacidad en el ámbito laboral.

\section{TABLA I. Evolución de la tasa de actividad, empleo y paro (\%)}

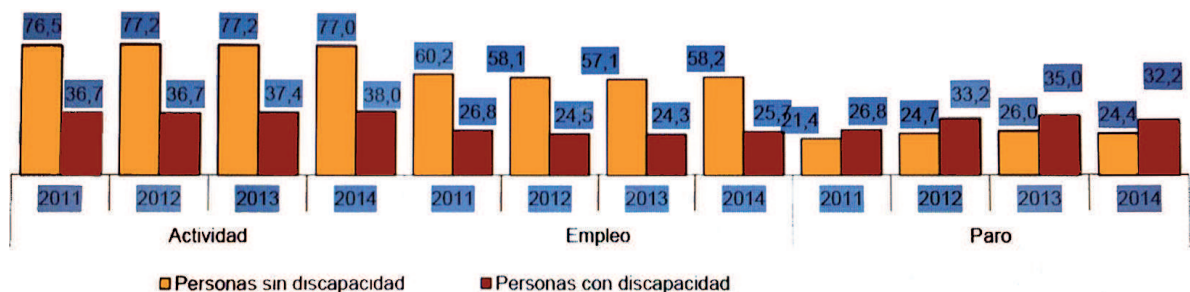

Fuente: Instituto Nacional de Estadística 2014

El número de personas con discapacidad ocupadas en 2014 era de 343.300. La tasa desempleo era del $25,7 \%$, más de 32 puntos inferior a la de las personas sin discapacidad. La tasa de paro superó en casi ocho puntos a la de la población sin discapacidad (32,2\% frente $24,4 \%$ ). Se observa un descenso de la tasa de paro respecto al año 2013 superior al experimentado por la de las personas sin discapacidad.

Para concluir este artículo y como reflexión personal me gustaría finalizar diciendo que solo existirá una verdadera protección social hacia las personas con discapacidad si se logra garantizar el principio de igualdad y no discriminación que encuentra su base en el derecho a la igualdad, tanto desde un punto de vista formal como material, recogido así en todos las declaraciones de derechos y textos constitucionales. Si se lograse de facto dicha premisa, la inclusión social de este colectivo sería plena y absoluta. Para ello las sociedades avanzadas y democráticas tiene a su alcance un sinfín de medidas cuyo cumplimento hace posible que ello sea una realidad. No puede olvidarse que la accesibilidad, la educación y el empleo, entre otras, son herramientas de progreso y de desarrollo, que han de emplearse como medio catalizador de promoción y oportunidad para las personas con discapacidad ya que sin género de duda, les proporcionará una vida en igualdad de condiciones, autónoma e independiente. 


\section{Bibliografía}

ARNAIZ, P. (2007) La atención a la diversidad: programación curricular, Madrid, Universidad Estatal a distancia.

AnNAN, K. (2001) recuperado de: Comisión de Desarrollo Social Informe sobre el $39^{\circ}$ período de sesiones (13 a 23 de febrero de 2001), Consejo Económico y Social, Documentos Oficiales, Suplemento $n^{\circ} 6$.

BARRANCO, M. C. (2001) Diversidad de situaciones y universalidad de los derechos, Madrid, Dykinson.

Becerra Traver, M. T. (2012) "Programas de orientación y empleo con apoyo de personas con discapacidad, modelos y estrategias de intervención", REOP, Vol. $23, n^{\circ} 3$, cuatrimestre, pp. 9-15.

Воввіо, N. (1993) Igualdad y Libertad, Barcelona, Paidos.

CABRA DE LUNA, M. A. (2011) "Discapacidad y aspectos sociales: la igualdad de oportunidades, la no discriminación y la accesibilidad universal como ejes de una nueva política a favor de las personas con discapacidad y sus familias. Algunas consideraciones en materia de protección", Revista del Ministerio de Trabajo y Asuntos Sociales, Madrid.

CÉspedes, A. (2007) "Políticas Sociales, Educación y Ciudadanía", Revista de Educación Social.

De Asís RoIG, R. (2013) “Unas primeras reflexiones sobre la Ley General de Derechos de las Personas con Discapacidad", Instituto de Derechos Humanos Bartolomé de las Casas, $n^{\circ}$ 12, Universidad Carlos III, Madrid, p. 5.

GIMÉNEZ GLUCK, D. (2010) "Asociación, Discriminación y Constitución" en Revista de Derecho Político, Madrid, $n^{\circ} 79$.

GonzÁlez Ortega, S. (2012) Derechos Sociales, políticas públicas y financiación autonómica a raíz de los nuevos estatutos de autonomía: La protección social en los nuevos estatutos de autonomía. El caso del Estatuto de Autonomía para Andalucía, Valencia, Tirant lo Blanch.

Jiménez Aparicio, E. (2009) Comentarios a la legislación de contratación pública, Madrid, Aranzadi. 
Martínez Abelán, R. (2010), "Una aproximación a la educación inclusiva en España", Revista de Educación Incluida, vol. 3, Murcia, p. 152.

Pérez Bueno, L. C, (2010). Discapacidad, Inclusión y Tercer Sector, Madrid, Cermi.

Pérez Bueno, L. C (2011). "Accesibilidad Universal y Diseño para todos", Fundación ONCE para la cooperación e inclusión social de personas con discapacidad, $1^{a}$ edición, Madrid, pp. 235-245.

RiBOTA, S. (2006). Educación en derechos humanos: la asignatura pendiente, Madrid, Dykinson.

Tuset, P. (2011), Cincuenta Cuestiones Básicas en Materia de Personas con Discapacidad, Madrid, Difusión Jurídica.

Vega, A. y López, M. (2011). "Personas con discapacidad: desde la exclusión a la plena ciudadanía" en Intersticios, Revista Sociológica de Pensamiento Crítico, Madrid, Volumen 5.

Villalobos, E. y Zalakain, J. (2010) "Discapacidad, Inclusión y Tercer Sector, Madrid, Cermi. 


\section{DOSSIER}

\section{POR UNA ECONOMÍA GLOBAL JUSTA}

\section{Introducción. La economía justa y la construcción de sociedades sostenibles e inclusivas}

Eduardo Ibáñez Ruiz del Portal y M. Carmen López Martín'

\begin{tabular}{|c|c|}
\hline \multirow{2}{*}{ NP 121, 2016/1 } & Índice \\
\hline & 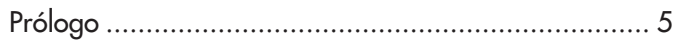 \\
\hline Promotio lustitiae & 1. Introducción: una llamada a la acción ................... 7 \\
\hline \multirow{4}{*}{$\begin{array}{l}\text { Por una economía global justa } \\
\text { Construir sociedades } \\
\text { sostenibles e inclusivas }\end{array}$} & 2. Signos de los tiempos.................................. 9 \\
\hline & $\begin{array}{l}\text { 3. Principales retos actuales................................ } 12 \\
\text { 3.1. El reto de la pobreza severa ....................... } 12 \\
\text { 3.2. La herida social de la desigualdad .............. } 14 \\
\text { 3.3. Los riesgos de la financiarización }\end{array}$ \\
\hline & contemporánea \\
\hline & $\begin{array}{l}\text { 3.4. La injusticia de la violencia ....................... } 18 \\
\text { 3.5. La fragilidad desatendida de la casa común.. } 20\end{array}$ \\
\hline \multirow{4}{*}{ Grupo de Trabajo sobre Economía } & 4. Una nueva visión ..................... \\
\hline & 4.1. El bien común, hoy ................................. 23 \\
\hline & 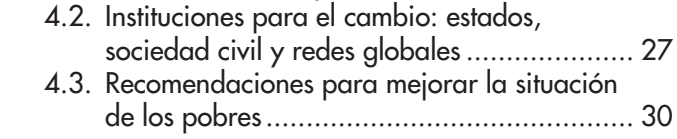 \\
\hline & 5. Recomendaciones para la familia ignaciana ......... 35 \\
\hline \multirow[t]{2}{*}{ 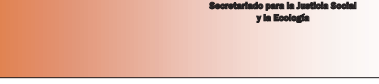 } & Abreviaturas utilizadas..... \\
\hline & Agradecimientos.... \\
\hline
\end{tabular}

'Profesores. Departamentos de Humanidades y Filosofía y de Economía, Universidad Loyola Andalucía. 